\title{
Transient and persistent symptoms in patients with lacunar infarction: results from a prospective cohort study
}

\author{
Ye-Ting Zhou' \\ Guang-Sheng Wang ${ }^{2}$ \\ Xiao-Dong Chen ${ }^{2}$ \\ Tong-Hui Yang ${ }^{2}$ \\ Dao-Ming Tong ${ }^{2,3}$ \\ 'Department of Clinical Research, \\ 2Department of Neurology, \\ Affiliated Shuyang People' Hospital, \\ XuZhou Medical University, Jiangsu, \\ ${ }^{3}$ Department of Neurology, the \\ Affiliated Pingxiang Hospital, Southern \\ Medical University, Pingxiang, People's \\ Republic of China
}

This article was published in the following Dove Press journal: Journal of Multidisciplinary Healthcare 24 November 2015

Number of times this article has been viewed
Background: The transient symptoms with lacunar infarction (TSI) and persistent symptoms with lacunar infarction (PSI) are the most common forms of symptomatic lacunar infarction (LI). The aim of this study was to compare the differences in TSI and PSI of symptomatic LI. Methods: A prospective cohort study was conducted in the neurologic outpatients of the tertiary teaching hospital in Northern China between February 2011 and February 2012. The TSI and PSI in participants aged 35 years or over were assessed. Patients were followed up and their outcomes were compared.

Results: Of the 453 symptomatic outpatients, 251 patients with LI were diagnosed by magnetic resonance imaging. Approximately 77.3\% (194/251) of the patients with LI at this time had TSI. and the remaining $23.7 \%$ had PSI. After the adjusted odds ratios, only middle age (risk ratio [RR], 1.1; 95\% confidence interval [CI], 1.157-1.189), lower National Institutes of Health Stroke Scale score (RR, 20.6; 95\% CI, 6.705-13.31), smaller lacunae on brain images (RR, 2.9; $95 \% \mathrm{CI}, 1.960-4.245)$, and LI frequently in the anterior circulation territory (RR, $0.2 ; 95 \% \mathrm{CI}$, 0.079-0.721) were independently associated with TSI. During a mean follow-up of 6 months, survival rate was significantly higher among patients with TSI than among those with PSI (log rank, $6.9 ; P=0.010)$; estimated unadjusted incidence of vascular subsequent events $(30.9 \% \mathrm{vs}$ $54.4 \%, P=0.001$ ) was significantly lower in TSI than in PSI.

Conclusion: The TSI has a higher prevalence and is associated with a lower risk of vascular subsequent events and death than PSI. The implications of these findings for TSI and PSI may require different interventions.

Keywords: lacunar infarction, magnetic resonance imaging, ischemic stroke, outcome

\section{Introduction}

With the progress of magnetic resonance imaging (MRI), the new definitions for transient ischemic attack (TIA) were proposed. ${ }^{1}$ Furthermore, the transient nonlocal symptoms were introduced. ${ }^{2}$ Symptomatic lacunar infarction (LI) is a common type of ischemic infarction in the literature. Although symptomatic LI represents a significant burden of symptomatic cases presenting to neurologic services, many of them were transient symptoms with LI (TSI) and were treated either in the township health centers or in the neurologic outpatients, whereas most hospitalized LI cases were often from frequent transient symptoms or persistent symptoms with LI (PSI). ${ }^{3-5}$ Consequently, those PSI were associated with potentially threatening sequelae, especially non-small artery disease. ${ }^{4-6}$ However, very little information has been reported on the differences between transient and persistent symptoms in patients with LI. The data currently are
Correspondence: Dao-Ming Tong Department of Neurology, Affiliated Shuyang People' Hospital, XuZhou Medical University, No 9, Yingbin Road, Shu town, Jiangsu, People's Republic of China Email tongdaoming@I63.com 
from a neurologic outpatient source in Northern China. The aim of this study was to clarify the differences in TSI and PSI of symptomatic LI.

\section{Methods}

This was a prospective observational study. All were registered neurologic outpatients of the tertiary teaching hospital in Shuyang in Northern China between February 2011 and February 2012. A total of 453 outpatients, clinically having their first-ever visit due to presenting with one of the five classical lacunar syndromes, or nonfocal or mixed symptoms, such as headache and dizziness, which can be attributed to an acute stroke, and who underwent MRI study of the brain, were enrolled. The upper limit of LI is usually defined as less than $15 \mathrm{~mm}$ in diameter. In the current, radiographic infarct is included in the definition of stroke. Furthermore, the diagnostic criteria of recent LI on MRI has been proposed: ${ }^{7} 1$ ) a round or an ovoid lesion of increased signal relative to white or deep gray matter on diffusion-weighted images (DWI) or fluid-attenuated inversion recovery (FLAIR); 2) hypointensity on the apparent diffusion coefficient map; 3) maximum diameter $\leq 20 \mathrm{~mm}$; and 4) location in cerebral hemispheric white matter, in basal ganglia, or in the brain stem. Thus, we defined recent LI as $\leq 20 \mathrm{~mm}$ in diameter on MRI-DWI and/or FLAIR. Exclusion criteria were as follows: 1 ) age $<35$ years; 2) patients without symptoms; 3 ) infarct size $<2 \mathrm{~mm}$ or $>20 \mathrm{~mm}$ on MRI; 4) earlier diagnosis of ischemic stroke.

All the patients underwent MRI of the brain, performed with 1.5-T equipment (Siemens AG, Munich, Germany). The MRI sequences included conventional T2, FLAIR and DWI on axial view (DWI performed for $51 \%$ of all patients), from medulla to cortex, at $5 \mathrm{~mm}$ section thickness. All MR studies were reviewed by a neuroradiologist and a neurologist. The examiners looked specifically for hyperintense lesions on FLAIR or DWI. The number and location of lesions on MRI were recorded in detail for each patient.

Referring to the Oxfordshire Community Stroke Project standard, the symptomatic LI in the brain was divided into two territories: anterior circulation territory (involving the cortex, subcortical, or basal ganglia) and posterior circulation territory (occipital lobes, thalamus, brainstem, or cerebellum).

According to patients' symptoms lasting $<24$ hours or $>24$ hours in duration, the study population was divided into two groups: patients with TSI and PSI patients. The National Institutes of Health Stroke Scale (NIHSS) was used to assess the severity of each LI group. For outcome analyses, follow-up information was gathered retrospectively by a neurological specialist, who conducted inquiries by phone until July 30, 2013. The patients given antiplatelet therapy were monitored, and vascular subsequent events (VSE) during 180 day follow-up were assessed. The study was approved by the Ethical Committee on Clinical Research of the Shuyang People' Hospital, People's Republic of China. Moreover, the study was in full compliance with the Helsinki declaration, and written informed consent was obtained from each patient.

\section{Related definition}

The definition of symptoms classified as shown in Table 1. The syndromes classified by Fisher, namely pure sensory stroke, pure motor hemiparesis, ataxic hemiparesis, dysarthria-clumsy hand, and sensorimotor stroke, were included in this study. The nonlocal symptoms such as isolated headache or dizziness which can be attributed to the LI, were defined as follows.

Headache/migraine is a common complaint for patients with cerebrovascular disease and is a common symptom of transient or persistent stroke. ${ }^{8-10}$ Duration of symptoms can be from minutes to hours (generally $<24$ hours), although some may be recurrent or continuous for a few days.

Dizziness/vertigo is also a common cerebrovascular symptom. ${ }^{11-13}$ Dizziness or vertigo is often present in transient symptoms (lasting seconds to minutes or hours; usually $<24$ hours) and may occur in continuous repeated episodes, or persistent episodes, lasting more than a few days.

Dizziness and headache may develop alternately or together. This dual symptom reflects a disorder of the anterior circulation, alone or in combination with a posterior circu-

Table I Definition of symptomatology

\begin{tabular}{|c|c|}
\hline Term & Definition \\
\hline $\begin{array}{l}\text { Transient ischemic } \\
\text { attack (TIA) }\end{array}$ & $\begin{array}{l}\text { TIA is a transient episode of neurological } \\
\text { dysfunction caused by focal brain, spinal cord, or } \\
\text { retinal ischemia without acute infarction' }\end{array}$ \\
\hline $\begin{array}{l}\text { Transient symptoms } \\
\text { with LI (TSI) }\end{array}$ & $\begin{array}{l}\text { Defined as focal or nonfocal cerebrovascular } \\
\text { symptoms lasting less than } 24 \text { hours and patients } \\
\text { with LI on DWI or FLAIR }\end{array}$ \\
\hline $\begin{array}{l}\text { Persistent symptoms } \\
\text { with LI (PSI) }\end{array}$ & $\begin{array}{l}\text { PSI Defined as focal or nonfocal cerebrovascular } \\
\text { symptoms lasting more than } 24 \text { hours and } \\
\text { patients with LI on DWI or FLAIR }\end{array}$ \\
\hline White matter lesions & $\begin{array}{l}\text { Defined as bilateral, symmetrical, and diffuse } \\
\text { hyperintensities, which were located in the } \\
\text { subcortical and periventricular white matter with } \\
\text { T2-weighted images and prone density images }\end{array}$ \\
\hline $\begin{array}{l}\text { Vascular subsequent } \\
\text { events (VSE) }\end{array}$ & $\begin{array}{l}\text { VSE defined as TIAs, transient nonfocal } \\
\text { cerebrovascular symptoms or deterioration } \\
\text { of cerebrovascular symptoms or recurrent } \\
\text { infarction, and plus a modified Rankin scale } \\
\text { (mRS) } \geq 2 \text { scores during a follow-up }\end{array}$ \\
\hline
\end{tabular}

Abbreviations: DWI, diffusion-weighted images; FLAIR, fluid-attenuated inversion recovery; LI, lacunar infarction. 
latory problem. In an outpatient setting, patients' dizziness and headache were usually lasting minutes to hours $(<24$ hours); but they may be recurrent and persist for several days or longer.

\section{Vascular risk factors}

Vascular risk factors were defined as follows: body mass index (BMI) measured at baseline was categorized as normal (BMI $<25 \mathrm{~kg} / \mathrm{m}^{2}$ ), overweight $\left(25-30 \mathrm{~kg} / \mathrm{m}^{2}\right)$, or obese $\left(>30 \mathrm{~kg} / \mathrm{m}^{2}\right)$; current smoking (within the last 5 years); hypertension (earlier or present use of antihypertensive agents or a systolic blood pressure $>140 \mathrm{mmHg}$ and/or a diastolic blood pressure $>90 \mathrm{mmHg}$, measured in a sitting position with least amount of antihypertensive medication); diabetes (fasting plasma glucose level $\geq 7.0 \mathrm{mmol} / \mathrm{L}$, hemoglobin A1c concentration $\geq 6.5 \%$, or random plasma glucose $>11.1 \mathrm{mmol} / \mathrm{L}$, associated with symptoms of hyperglycemia); hyperlipidemia (total venous plasma cholesterol level $>6.0 \mathrm{mmol} / \mathrm{L}$, low density lipoprotein fraction $>3.0$ $\mathrm{mmol} / \mathrm{L}$, high density lipoprotein fraction $<1.0 \mathrm{mmol} / \mathrm{L}$, triglyceride level $>1.8 \mathrm{mmol} / \mathrm{L}$ ); atrial fibrillation (present when seen on an electrocardiogram during the initial visit or when it was reported in medical records); and a history of coronary and peripheral artery disease.

\section{Statistical analysis}

All numeric variables were expressed as the mean $\pm \mathrm{SD}$ or median (interquartile range). Fisher's exact test was used to explore the relationship between baseline patient variables. Continuous variables were compared using the $t$-test. Bivariate logistic regression analyses for risk factors were used to calculate risk ratios (RRs), 95\% confidence intervals (CIs), and probability values. Kaplan-Meier method and test were used to estimate the differences in survival between groups, and VSE by the log-rank test. Data were analyzed using SPSS version 17.0 (SPSS Inc., Chicago, IL, USA), with level of significance set at $P<0.05$.

\section{Results}

All the 453 outpatients enrolled completed the study, and 251 patients with symptomatic LI were diagnosed by brain MRI. Of the 251 (55.4\%) LI patients, TSI was observed in up to $77.3 \%$ (194/251) of the patients, and remaining $23.7 \%$ was PSI. There were no significant differences in the periodic duration of TSI group when compared with PSI group (median 20 vs $7 \mathrm{~d}, P>0.05)$. The incidence rate of symptomatic LI increased with age, and this was different among patients with TSI than those with PSI $(P=0.000)$, with incidence peaking in the age group of 45-64 years for the TSI group, while the PSI group, the peak incidence occurs in the 65-75 years older population. However, unadjusted odds ratio for patients who were younger than 65 years of age and patients who were 65 years of age or older showed that only higher BMI (RR, 0.887; 95\% CI, $0.805-0.977 ; P=0.015)$ and shorter duration of hypertension (RR, 1.072; 95\% CI, 1.015-1.133; $P=0.012$ ) were independent prediction factors for prevalence of TSI.

Demographics and baseline characteristics in patients with TSI and those with PSI were compared. The most common transient symptoms of TSI were isolated dizziness/vertigo $(30.9 \%)$ and headache/migraine $(28.4 \%)$. The most frequent persistent symptoms of PSI were headache with dizziness (35.1\%) and isolated dizziness/vertigo (29.8\%), whereas pure sensory stroke $(13.1 \%)$, pure motor hemiparesis $(4.0 \%)$, sensorimotor syndrome $(0.4 \%)$, ataxic hemiparesis $(0.4 \%)$, and dysarthria-clumsy hand $(0.4 \%)$ syndrome as well as cognitive impairment were not common. In univariate analysis, age, duration of hypertension, headache/migraine, pure motor hemiparesis, gait disorders, number of lesions on MRI, size of lacunae on MRI, lesions in the anterior circulation territory, lesions in the anterior and posterior circulation, white matter lesions, initial NIHSS score, ABCD2 score, mortality, and VSE were directly associated with TSI and PSI (Table 2). However, in a logistic regression model by forwards stepwise regression analyses, only age (RR, 1.1; 95\% CI, 1.157-1.189), initial NIHSS score (RR, 20.6; 95\% CI, 6.705-13.31), size of lacunae on DWI or FLAIR imaging (RR, 2.9; 95\% CI, $1.960-4.245)$, and LI frequently in the anterior circulation territory (RR, 0.2; 95\% CI, 0.079-0.721) were independently associated with TSI or PSI (Table 3).

During a 6-month follow-up, survival data were available for our patients with LI (only two cases were lost to follow-up). A total of $3.5 \%$ of patients with PSI due to the recurrent atherosclerotic infarction died during follow-up. Survival rate was significantly higher among patients with TSI than among those with PSI (log rank, 6.9; $P=0.010$ ) (Figure 1).

The unadjusted incidence for VSE in the TSI was significantly lower than in the PSI ( $30.9 \%$ vs $54.4 \%, P=0.000)$. The unadjusted RR for VSE in the TSI when compared with PSI was 10.9 (95\% CI, 7.2-17.5; P=0.001) (Figure 2). Independent predictor identified from a logistic regression model by forwards stepwise regression analyses for VSE was only age (OR, 1.1; 95\% CI, 1.064-1.126; $P=0.000)$.

\section{Discussion}

The current status reported in this study for the incidence of symptomatic LI of $55.4 \%$, and the incidence of TSI of $77.3 \%$ (194/251) in Shuyang in Northern China, must be considered to be minimum figures. Atherosclerosis (small 
Table 2 The baseline characteristics in LI patients with TSI and PSI

\begin{tabular}{|c|c|c|c|c|}
\hline Episodes & All $(n=25 I)$ & TSI $(n=\mid 94)$ & PSI $(n=57)$ & $P$-value \\
\hline \multicolumn{5}{|l|}{ Risk factors } \\
\hline Male sex (\%) & $125(49.8)$ & $92(47.4)$ & $33(57.9)$ & 0.164 \\
\hline Age (years, mean $\pm S D$ ) & $60.2 \pm 11.3$ & $58 \pm 10.3$ & $68 \pm 10.9$ & 0.000 \\
\hline BMI $\left(\mathrm{kg} / \mathrm{m}^{2}\right.$, mean $\left.\pm \mathrm{SD}\right)$ & $24.0 \pm 3.2$ & $24.1 \pm 3.3$ & $23.4 \pm 2.5$ & 0.290 \\
\hline Duration of hypertension (years, mean $\pm S D$ ) & $3.1 \pm 5.0$ & $2.7 \pm 4.4$ & $4.4 \pm 6.6$ & 0.020 \\
\hline Diabetes mellitus (\%) & $20(8.0)$ & $14(7.2)$ & $6(10.5)$ & 0.417 \\
\hline Dyslipidemia (\%) & I 44 (57.4) & $106(54.6)$ & $38(66.7)$ & 0.106 \\
\hline Heart disease (\%) & $7(3.0)$ & $4(2.1)$ & $3(5.3)$ & 0.197 \\
\hline Atrial fibrillation (\%) & $2(0.8)$ & $2(1.0)$ & $0(0)$ & 0.442 \\
\hline Current smoking (\%) & $62(24.7)$ & $46(23.7)$ & $16(28.1)$ & 0.502 \\
\hline Heavy alcohol drinker (\%) & $6 \mathrm{I}(24.3)$ & $51(26.3)$ & $10(17.5)$ & 0.176 \\
\hline \multicolumn{5}{|l|}{ Symptoms features } \\
\hline Periodic duration of episodes (days, range) & $147(0.1-2,879)$ & $20(0.2-2,880)$ & $7(0.1-I, 080)$ & 0.307 \\
\hline Headache/migraine (\%) & $56(22.3)$ & $55(28.4)$ & $\mathrm{I}(\mathrm{I} .8)$ & 0.000 \\
\hline Dizziness/vertigo (\%) & $77(30.7)$ & $60(30.9)$ & $17(29.8)$ & 0.874 \\
\hline Headache and dizziness (\%) & $7 I(28.3)$ & $53(27.3)$ & $18(31.6)$ & 0.530 \\
\hline Pure sensory stroke (\%) & $33(13.1)$ & $22(11.3)$ & II (19.3) & 0.118 \\
\hline Pure motor hemiparesis (\%) & $10(4.0)$ & $2(1.0)$ & $8(14.0)$ & 0.000 \\
\hline Sensorimotor syndrome (\%) & $\mathrm{I}(0.4)$ & $0(0)$ & $\mathrm{I}(\mathrm{I} .8)$ & 0.065 \\
\hline Ataxic-hemiparesis (\%) & $\mathrm{I}(0.4)$ & $\mathrm{I}(0.5)$ & $0(0)$ & 0.587 \\
\hline Dysarthria-clumsy hand (\%) & $\mathrm{I}(0.4)$ & $\mathrm{I}(0.5)$ & $0(0)$ & 0.587 \\
\hline Cognitive impairment (\%) & $\mathrm{I}(0.4)$ & $0(0)$ & $\mathrm{I}(\mathrm{I} .8)$ & 0.065 \\
\hline Median number of lesions on MRI (range) & $10.6(1-109)$ & $5.6(I-48)$ & $13(I-|| 0)$ & 0.000 \\
\hline Median size of lacular (mm, range) & $5.0(2-9)$ & $4(2-10)$ & $7.5(2-20)$ & 0.000 \\
\hline Anterior circulation (\%) & $140(55.8)$ & $122(62.9)$ & $18(3 \mid .6)$ & 0.000 \\
\hline Posterior circulation (\%) & $8(3.2)$ & $6(3.1)$ & $2(3.5)$ & 0.875 \\
\hline Anterior and posterior circulation (\%) & $113(45.0)$ & $66(34.0)$ & $37(64.9)$ & 0.000 \\
\hline White matter lesions (\%) & $12(4.8)$ & $6(3.1)$ & $8(14.0)$ & 0.002 \\
\hline Initial median NIHSS score (range) & $0.7(0-6)$ & $0.05(0-2)$ & I (0-3) & 0.000 \\
\hline Initial $A B C D 2$ score (mean $\pm S D$ ) & $5.0 \pm 1.2$ & $4.8 \pm 1.1$ & $6.0 \pm 1.0$ & 0.000 \\
\hline Mortality (\%) & $2(0.8)$ & $0(0)$ & $2(3.5)$ & 0.009 \\
\hline Vascular subsequent event (\%) & $91(36.3)$ & $60(30.9)$ & $31(54.4)$ & 0.000 \\
\hline
\end{tabular}

Note: Scores range from 0 to 7, with higher scores indicating greater risk of stroke.

Abbreviations: BMI, body mass index; LI, lacunar infarction; MRI, magnetic resonance imaging; NIHSS, National Institutes of Health Stroke Scale; PSI, persistent symptoms with LI; TSI, transient symptoms with LI; ABCD2, age, blood pressure, clinical features, duration of symptoms, and presence or absence of diabetes.

vessel and large vessel sclerosis) was associated with increasing prevalence of lacunar infarcts, ${ }^{14-17}$ but it has been difficult to dissociate these risk factors. ${ }^{5,14,18}$ Similarly, in this study, these risk factors lead to acceleration of the atherosclerosis process of TSI and PSI. There was significant difference only in age and duration of hypertension in both groups. The patients with TSI were younger than those with PSI. The unadjusted odds ratio for $\leq 64$ years of age and $\geq 65$ years of age suggest that both factors are important for TSI. The prevalence rates were of shorter duration of hypertension and increased BMI, which are commonly associated with TSI. In our analysis, the prevalence of TSI with incidence peaking at the age group of 45-64 years; this may be a common precipitant of TSI. This difference in ages should be due to variations in atherosclerotic burden. Furthermore, age differences in distribution and incidence of symptomatic LI have been confirmed by an earlier study. ${ }^{18}$ Therefore, those with atherosclerotic burden, whether TSI or

Table 3 Multivariate analysis of the association of the early predictors for LI patients with TSI and PSI

\begin{tabular}{lllll}
\hline Episodes & TSI $(\mathbf{n = 1 9 4 )}$ & PSI (n=57) & RR (95\% CI) & P-value \\
\hline Age (years, mean \pm SD) & $58 \pm 10.3$ & $68 \pm 10.9$ & $1.1(1.157-1.189)$ & 0.000 \\
Initial median NIHSS score (range) & $0.05(0-2)$ & $\mathrm{I}(0-4)$ & $20.6(6.705-13.3 \mathrm{I})$ & 0.000 \\
Median size of lacunae on MRI (mm, range) & $4(2-10)$ & $7.5(2-20)$ & $2.9(1.960-4.245)$ & 0.000 \\
LI in anterior circulation (\%) & $122(62.9)$ & $18(31.6)$ & $0.2(0.079-0.721)$ & 0.011 \\
\hline
\end{tabular}

Abbreviations: $\mathrm{Cl}$, confidence interval; LI, lacunar infarction; MRI, magnetic resonance imaging; NIHSS, National Institutes of Health Stroke Scale; PSI, persistent symptoms with LI; RR, risk ratio; TSI, transient symptoms with LI. 


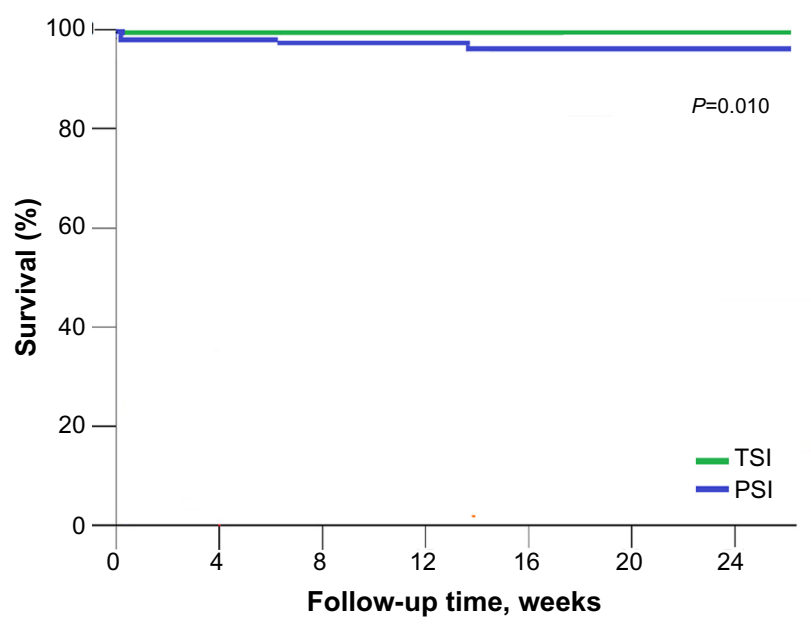

Figure I Kaplan-Meier survival curves for patients with TSI and PSI. Abbreviations: LI, lacunar infarction; PSI, persistent symptoms with LI; TSI, transient symptoms with LI.

PSI, have been considered to be the pathological changes of cardiovascular and cerebrovascular, including small vessel disease, larger vascular stenosis or occlusion, or cardiogenic emboli. ${ }^{5,6,17,19}$

The TIA is at a higher risk of stroke, ${ }^{1}$ and almost $1 / 3$ of TIA preceding a stroke. ${ }^{20,21}$ Similarly, most of the patients with transient nonlocal symptoms are also at a high risk of stroke. ${ }^{2}$ Previous studies indicated transient symptoms with abnormal lesion on DWI were called the "transient symptoms with infarction" (TSI). ${ }^{22}$ According to our outpatients setting observations, the current report showed that almost 95\% of TSI patients who confirmed by FLAIR or DWI were associated with the nonfocal and mixed transient symptoms. The finding suggests that those FLAIR or DWI abnor-

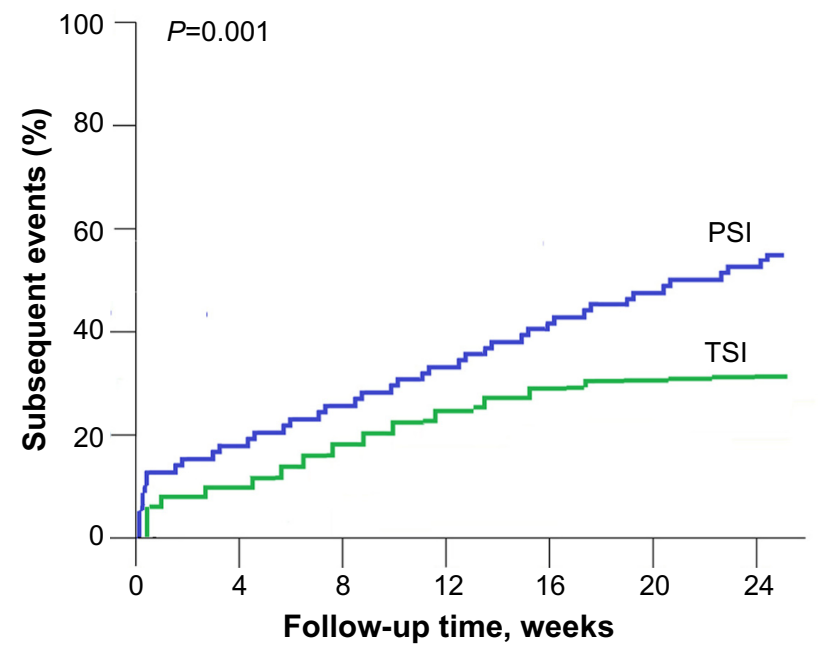

Figure 2 Kaplan-Meier subsequent events curves for patients with TSI and PSI. Abbreviations: LI, lacunar infarction; PSI, persistent symptoms with LI; TSI, transient symptoms with LI. malities among nonfocal and mixed transient symptomatic patients can essentially be attributed to TSI. An earlier study has shown that dysarthria-clumsy hand and pure sensory stroke are the traditional lacunar syndromes with a better clinical course, being symptom-free at discharge in $45.7 \%$ and $41.5 \%$ of cases, respectively. ${ }^{23,24}$ In present study, those TSI patients with nonfocal symptoms may be more likely to have a benign or mild course. In fact, these frequent transient symptoms such as isolated dizziness/vertigo and headache/ migraine variants have not been classified as common atypical lacunar syndromes. Therefore, it is noted that the common symptoms of symptomatic LI in our neurologic outpatients should have some new variants.

An earlier study indicated that cognitive impairment should be considered as a common clinical feature in multiple LI and white matter lesions. ${ }^{25}$ Our study showed that white matter lesions and multiple lacunar infarct in PSI were higher than those for TSI, but cognitive impairment was rare. Recent study has shown that cognitive impairment usually occurred a year later of LI onset, ${ }^{26}$ and some of the earlier studies indicated that its mean time course may be 4 years later or longer. ${ }^{25,27}$ The median duration in our current patients was 147 days, and the median duration among PSI was only seven days. Thus, in our series, a rare cognitive impairment is understandable. Moreover, the time course in our patients supported that a longer time course may increase the likelihood of developing cognitive impairment.

Estimated adjusted odds ratios found that middle age, lower NIHSS score, smaller lacunae on brain FLAIR, and lesions more frequently in the anterior circulation were several factors independently associated with a higher risk of TSI. The findings showed that small vessel disease or carotid plaque may be the cause of TSI. This has been recognized in the earlier studies. ${ }^{14,16,17}$ In contrast, the same several factors, as older age, higher NIHSS score, larger lacunae, and lesions more frequently in the anterior circulation or spreading to the posterior circulation were independently associated with a higher risk of PSI, and perhaps involved a more severe burden of atherosclerosis.,

In our study, the survival rate was $100 \%$ in TSI patients, whereas, in PSI patients, the survival rate was only $96.5 \%$, and the difference in two groups was significant. Moreover, the VSE in TSI group was significantly lower when compared with the PSI group. These findings indicate that most of TSI is usually benign or runs a mild course, while those PSI patients may be more likely to have a frequent VSE and have a high-risk of vascular death. An earlier study considered that hypertension and diabetes were significant factors 
related to recurrent LI. ${ }^{25}$ Currently this study showed that a long duration of hypertension may more likely relate to VSE. In fact, the frequency of VSE and worse outcomes have also been related to the intracranial artery stenosis or occlusion. 5,6,28,29 In addition, the study showed that older patients with ischemic stroke were easy to follow with worse outcomes. ${ }^{18}$ This has also been confirmed by our current study. Therefore, we believe that these findings may be important for symptomatic LI setting prevention and treatment measures.

Some limitations of our study are conceded. Instances of unexpected stroke are often routed directly by an ambulance to the intensive care unit, especially when the consciousness or motor function is involved (not uncommon). ${ }^{30,31}$ This may account for a lower frequency of patients with PSI in our general neurologic outpatients. In addition, the absence of a repeated MRI or vascular imaging data for many outpatients may have an effect on the exploration of patients with VSE.

In conclusion, TSI and PSI are two forms of symptomatic LI, and the TSI in neurologic outpatients had a higher prevalence than in patients with PSI. Clinically, the common symptoms of symptomatic LI had new variants. TSI had a benign course, whereas the PSI patients were associated with a worse outcome. The implications of these findings for TSI and PSI may require different interventions.

\section{Acknowledgment}

This work was supported by a grant from the Medical Research Council, Affiliated Shuyang People's Hospital, XuZhou Medical University, People's Republic of China.

\section{Disclosure}

The authors report no conflicts of interest in this work.

\section{References}

1. Easton JD, Saver JL, Albers GW, et al. Definition and evaluation of transient ischemic attack: a scientific statement for healthcare professionals from the American Heart Association/American Stroke Association. Stroke. 2009;40:2276-2293.

2. Bos MJ, van Rijn MJ, Witteman JC, Hofman A, Koudstaal PJ, Breteler MM. Incidence and prognosis of transient neurological attacks. JAMA. 2007;298:2877-2885.

3. Saji N, Shimizu H, Kawarai T, Tadano M, Kita Y, Yokono K. Clinical features of a first-ever lacunar infarction in Japanese patients: poor outcome in females. J Stroke Cerebrovasc Dis. 2011;20: 231-235.

4. Staaf G, Lindgren A, Norrving B. Pure motor stroke from presumed lacunar infarct: long-term prognosis for survival and risk of recurrent stroke. Stroke. 2001;32:2592-2596.

5. Baumgartner RW, Sidler C, Mosso M, Georgiadis D. Ischemic lacunar stroke in patients with and without potential mechanism other than small-artery disease. Stroke. 2003;34:653-659.
6. Bang OY, Heo JH, Kim JY, Park JH, Huh K. Middle cerebral artery stenosis is a major clinical determinant in striatocapsular small, deep infarction. Arch Neurol. 2002;59:259-263.

7. Potter GM, Marlborough FJ, Wardlaw JM. Wide variation in definition, detection, and description of lacunar lesions on imaging. Stroke. 2011;42:359-366.

8. Koudstaal PJ, van Gijn J, Kappelle LJ. Headache in transient or permanent cerebral ischemia. Dutch TIA Study Group. Stroke.1991;22: 754-759.

9. Bousser MG, Welch KM. Relation between migraine and stroke. Lancet Neurol. 2005;4:533-542.

10. Olesen J, Friberg L, Olsen TS, et al. Ischaemia-induced (symptomatic) migraine attacks may be more frequent than migraine-induced ischaemic insults. Brain. 1993;116:187-202.

11. Cloutier JF, Saliba I. Isolated vertigo and dizziness of vascular origin. J Otolaryngol Head Neck Surg. 2008;37:331-339.

12. Chang CC, Chang WN, Huang CR, Liou CW, Lin TK, Lu CH. The relationship between isolated dizziness/vertigo and the risk factors of ischemic stroke: a case control study. Acta Neurol Taiwan. 2011;20: 101-106.

13. Moubayed SP, Saliba I. Vertebrobasilar insufficiency presenting as isolated positional vertigo or dizziness: a doubleblind retrospective cohort study. Laryngoscope. 2009;119:2071-2076.

14. Hankey GJ. Long-term outcome after ischaemic stroke/transient ischaemic attack. Cerebrovasc Dis. 2003;16:14-19.

15. Markus HS, Khan U, BirnsJ, et al. Differences in stroke subtypes between black and white patients with stroke. The South London Ethnicity and Stroke Study. Circulation. 2007;116: 2157-2164.

16. Brisset M, Boutouyrie P, Pico F, et al. Large-vessel correlates of cerebral small-vessel disease. Neurology. 2013;80:662-669.

17. Fisher CM. Lacunar strokes and infarcts: a review. Neurology. 1982;32: 871-876.

18. Toni D, Di Angelantonio E, Di Mascio MT, Vinisko R, Bath PM. Types of stroke recurrence in patients with ischemic stroke: a substudy from the PRoFESS trial. Int J Stroke. 2014;9(7):873-878.

19. Wardlaw JM, Dennis MS, Warlow CP, Sandercock PA. Imaging appearance of the symptomatic perforating artery in patients with lacunar infarction: occlusion or other vascular pathology? Ann Neurol. 2001;50:208-215.

20. Ovbiagele B, kidwell CS, Saver JL. Epidemiological impact in the United States of a tissure-based definition of transient ischemic attack. Stroke. 2003;34:919-924.

21. Giles MF, Albers GW, Amarenco P, et al. Addition of brain infarction to the ABCD2 Score (ABCD2I): a collaborative analysis of unpublished data on 4574 patients. Stroke. 2010;41:1907-1913.

22. Ay H, Koroshetz WJ, Benner T, et al. Transient ischemic attack with infarction: a unique syndrome? Ann Neurol. 2005;57: 679-686.

23. Arboix A, Bell Y, García-Eroles L, et al. Clinical study of 35 patients with dysarthria-clumsy hand syndrome. J Neurol Neurosurg Psychiatry. 2004;75:231-234.

24. Arboix A, García-Plata C, García-Eroles L, et al. Clinical study of 99 patients with pure sensory stroke. J Neurol. 2005;252:156-162.

25. Arboix A, Font A, Garro C, García-Eroles L, Comes E, Massons J. Recurrent lacunar infarction following a previous lacunar stroke: a clinical study of 122 patients. J Neurol Neurosurg Psychiatry. 2007; 78: 1392-1394.

26. Anderson JF, Saling MM, Srikanth VK, Thrift AG, Donnan GA. Individuals with first-ever clinical presentation of a lacunar infarction syndrome: is there an increased likelihood of developing mild cognitive impairment in the first 12 months afterstroke? J Neuropsychol. 2008;2: 373-385.

27. Makin SD, Turpin S, Dennis MS, Wardlaw JM. Cognitive impairment after lacunar stroke: systematic review and meta-analysis of incidence, prevalence and comparison with other stroke subtypes. J Neurol Neurosurg Psychiatry. 2013;84:893-900. 
28. Purroy F, Montaner J, Rovira A, Delgado P, Quintana M, Alvarez-Sabin J. Higher risk of further vascular events among transient ischemic attack patients with diffusion-weighted imaging acute ischemic lesions. Stroke. 2004;35:2313-2319.

29. Marquardt L, Kuker W, Chandratheva A, Geraghty O, Rothwell PM. Incidence and prognosis of $\geq 50 \%$ symptomatic vertebral or basiilar artery stenosis: prospective population-based study. Brain. 2009;123:982-988.
30. Mosley I, Nicol M, Donnan G, Patrick I, Kerr F, Dewey H. The impact of ambulance practice on acute stroke care. Stroke. 2007;38:2765-2770.

31. Rosamond WD, Evenson KR, Schroeder EB, Morris DL, Johnson AM, Brice JH. Calling emergency medical services for acute stroke: a study of 9-1-1 tapes. Prehosp Emerg Care 2005;9(1):19-23.

\section{Publish your work in this journal}

The Journal of Multidisciplinary Healthcare is an international, peerreviewed open-access journal that aims to represent and publish research in healthcare areas delivered by practitioners of different disciplines. This includes studies and reviews conducted by multidisciplinary teams as well as research which evaluates the results or conduct of such teams or healthcare processes in general. The journal covers a wide range of areas and welcomes submissions from practitioners at all levels, from all over the world. The manuscript management system is completely online and includes a very quick and fair peer-review system. Visit http://www.dovepress.com/testimonials.php to read real quotes from published authors.

Submit your manuscript here: http://www.dovepress.com/journal-of-multidisciplinary-healthcare-journal 